\title{
Gut microbes in cardiovascular diseases and their potential therapeutic applications
}

\author{
Ling $\mathrm{Jin}^{1}$, Xiaoming $\mathrm{Shi}^{2}$, Jing Yang ${ }^{2}$, Yangyu Zhao ${ }^{2}$, Lixiang Xue ${ }^{1 \bowtie}, \mathrm{Li} \mathrm{Xu}^{3 \bowtie}$, Jun Cai ${ }^{4 \bowtie}$ \\ ${ }^{1}$ Center of Basic Medical Research, Institute of Medical Innovation and Research, Peking University Third Hospital, Beijing \\ 100191, China \\ 2 Department of Obstetrics and Gynecology, Peking University Third Hospital, Beijing 100191, China \\ ${ }^{3}$ Heart Center and Beijing Key Laboratory of Hypertension, Beijing Chaoyang Hospital, Capital Medical University, Beijing \\ 100043, China \\ ${ }^{4}$ Hypertension center of Fuwai Hospital, State Key Laboratory of Cardiovascular Disease, National Center for Cardiovascular \\ Diseases, Chinese Academy of Medical Sciences and Peking Union Medical College, Beijing 100037, China \\ $\square$ Correspondence: lixiangxue@hsc.pku.edu.cn (L. Xue), imxuli@hotmail.com (L. Xu), caijun@fuwaihospital.org (J. Cai) \\ Received May 5, 2020 Accepted August 19, 2020
}

\begin{abstract}
Microbial ecosystem comprises a complex community in which bacteria interact with each other. The potential roles of the intestinal microbiome play in human health have gained considerable attention. The imbalance of gut microbial community has been looked to multiple chronic diseases. Cardiovascular diseases (CVDs) are leading causes of morbidity worldwide and are influenced by genetic and environmental factors. Recent advances have provided scientific evidence that CVD may also be attributed to gut microbiome. In this review, we highlight the complex interplay between microbes, their metabolites, and the potential influence on the generation and development of CVDs. The therapeutic potential of using intestinal microbiomes to treat CVD is also discussed. It is quite possible that gut microbes may be used for clinical treatments of CVD in the near future.
\end{abstract}

KEYWORDS gut microbiota, cardiovascular diseases, action mechanism, therapeutic applications

\section{INTRODUCTION}

Cardiovascular diseases (CVDs) have taken center stage as the leading causes of morbidity and mortality worldwide. The cause of CVD is still under investigation, but thought to be influenced by genetic and environmental factors.
Recent studies have shed light on the potential roles of the intestinal microbiome in CVD. Microbes in the intestine vastly outnumber the total number of human cells. They form a complex community of interacting organisms and are even collectively regarded as a human organ (Clemente et al., 2012). Starting at childbirth, many factors influence the composition, metabolism and functions of this microbial community. Many studies have indicated that gut microbiome imbalance may play a role altering CVDs susceptibility by influencing aspects of the immune response, obesity, insulin resistance, atherosclerosis and thrombosis susceptibility factors. The microbita may also communicate with distal host organs through their metabolites (Tang and Hazen, 2017).

In this review, we summarize the complex interplay between microbes (and their metabolites) and their potential roles in the generation and development of CVDs. Moreover, possible therapeutic strategies for modulating the intestinal microbes to alter the generation and development of CVDs are discussed.

\section{MICROBIOTA DYSBIOSIS AND CVDS}

Microbiota dysbiosis refers to the imbalance in host-microbial interactions. Changes in either microbial composition or community-derived factors (such as metabolites or genotoxins) can be directly or indirectly associated with enhanced disease susceptibility. These microbiome based factors may cause activation of signaling pathways and ultimately lead to 
the pathophysiological diseases of CVDs. Moreover, these components have the potential to be targeted for therapeutic applications.

\section{Changes in gut microbial composition}

The gut microbiota consists of four major phyla: Firmicutes, Bacteroidetes, Actinobacteria and Proteobacteria. Bacteroidetes and Firmicutes together account for the majority of the gut community in healthy adults, and the Firmicutes/ Bacteroidetes ratio is viewed as a health indicator of intestinal microbiota (Qin et al., 2010). However, microbial composition differs between individuals and is dynamically sensitive to host factors as well as environment parameters. Interestingly, both increased abundance of host opportunistic pathogens (e.g., Escherichia coli, Clostridium ramosum, Bacteroides caccae, and Eggerthella lenta) and reduced abundance of short-chain fatty acid (SCFA) producing bacteria (e.g., Roseburia, Faecalibacterium and Eubacterium rectale) have been associated with increased risks for developing CVDs (Gozd-Barszczewska et al., 2017; Yan et al., 2017). Therefore, both the types of the microorganisms and their relative abundance are factors that may alter the sensitivity of developing CVDs (Franzosa et al., 2015).

Studies of microorganisms have been revolutionized since the introduction of bacterial genome analyses. Two sequencing methods, 16S rDNA sequencing and metagenomic sequencing, have commonly been used for assessment of microbial compositions and their relative abundance. $16 \mathrm{~S}$ sequencing detects differences in the hypervariable regions in bacterial genomes by targeting conserved regions that surround the variable regions. The main drawback of this technique is that it is insufficient for species-level resolution since their differences are often minor. On the contrary, shotgun metagenomics detect the entire genomes of all organisms at present, leading to increased sensitivity allowing the detection of both known and unknown microorganisms. In this part, we list changes of gut microbial composition associted with CVDs (Table 1).

\section{Atherosclerosis and coronary artery disease}

Atherosclerosis is a chronic inflammatory disease characterized by the dysfunction of vascular cells and the accumulation of lowdensity lipoprotein particles in plaques (Davignon and Ganz, 2004; Libby et al., 2002). Staphylococcus species, Proteus vulgaris, Klebsiella pneumoniae and Streptococcus species have been identified in both of the atherosclerotic lesions and the gut of the same individual, which suggest the involvement of gut microbiota (GM) in atherosclerosis development (Ott et al., 2006). Certain types of gut bacteria have been identified as novel contributors to the progression of atherosclerosis. Middleaged men in eastern Poland with improper total cholesterol levels and LDL-C values are rich in Prevotella, low of Clostridium and Faecalibacterium levels (Gozd-Barszczewska et al., 2017), while Chinese atherosclerotic cardiovascular disease patients show a relative reduction in Bacteroides and Prevotella, and enrichment in Streptococcus and Escherichia (Jie et al., 2017). The opportunistic pathogenic genus Collinsella has been found enhanced in patients with symptomatic atherosclerosis. Intriguingly, some microbial species reduce the risks of atherosclerotic plaque formation. For example, the relative depletion of butyrate-producing bacterial genus of Roseburia and Eubacterium have been found to be inversely correlated with atherosclerotic lesion development in patients and genetical mouse models (Karlsson et al., 2012; Kasahara et al., 2018). It is speculated that these microorganisms may influence the inflammatory status of the host. Moreover, colonization by diverse bacteria rather than a single pathogen can impact plaque formation and stability. The bacterial community in atherosclerotic plaque samples has been found to be correlated with clinical parameters such as total cholesterol, alanine aminotransferase and fibrinogen levels (Ziganshina et al., 2016). However, it is unclear which species play a leading role in the contributing CVDs. The mechanism of how the microbiota influences the atherosclerosis development is of great interest of future investigation (Jin et al., 2019).

\section{Hypertension}

High blood pressure is a prevalent cause of CVDs worldwide. The first evidence suggesting the involvement of gut microbiota in hypertension pathogenesis was observed in rats on the effect of antibiotic treatment on blood pressure (Honour et al., 1985). Subsequently, reduced levels of microbial richness, biodiversity and evenness have been identified in the fecal microbiota of hypertensive animal models and human patients. In addition, the severity of hypertension was found to be associated with the numbers of hypertension related bacterial species, increased Firmicutes/Bacteroidetes ratios, greater abundances of opportunistic pathogenic taxa (e.g., Klebsiella spp., Streptococcus spp.), and reduced populations of acetate-/butyrate-producing bacteria (Mell et al., 2015; Yan et al., 2017; Yang et al., 2015). It has been reported that microbial characteristics are similar between prehypertensive and hypertensive populations, with obvious overgrowth of Prevotella and Klebsiella bacteria in both groups (Li et al., 2017a). The abundance of butyrate producing genus Odoribacter and butyrate production are inversely associated with blood pressure levels in women with higher risk of developing pregnancy-induced hypertension and preeclampsia (Gomez-Arango et al., 2016).

Hypertensive gut microbiome exhibits increased membrane transport, lipopolysaccharide biosynthesis and steroid degradation. Dysbiosis of the microbiota might be partially mediated byvitamin D3 deficiency (Zuo et al., 2019c). Numerous studies have investigated the relationship between hypertension and GM in humans and in rat animal models (Adnan et al., 2017; Durgan et al., 2016; Li et al., 2017a; Mell et al., 2015). Santisteban et al. find that alterations in blood pressure relevant microbial communities may 
Table 1. Altered gut microbial compositions associated with CVDs

\begin{tabular}{|c|c|c|c|c|}
\hline \multirow[t]{2}{*}{ Species } & \multirow[t]{2}{*}{ Technique } & \multicolumn{2}{|c|}{ Illness-associated changes in gut microbial abundance } & \multirow[t]{2}{*}{ References } \\
\hline & & Decrease & Increase & \\
\hline \multicolumn{5}{|c|}{ Atherosclerosis and coronary artery disease } \\
\hline Human & $\begin{array}{r}\text { Metagenomic } \\
\text { sequencing }\end{array}$ & Bacteroides and Prevotella & $\begin{array}{l}\text { Streptococcus and } \\
\text { Escherichia }\end{array}$ & (Jie et al., 2017) \\
\hline Human & $\begin{array}{l}\text { Terminal } \\
\text { restriction } \\
\text { fragment length } \\
\text { polymorphism. }\end{array}$ & Bacteroides and Prevotella & Order Lactobacillales & $\begin{array}{l}\text { (Emoto et al., } \\
\text { 2016) }\end{array}$ \\
\hline Human & $\begin{array}{r}\text { Metagenomic } \\
\text { sequencing }\end{array}$ & Roseburia and Eubacterium & Collinsella & $\begin{array}{l}\text { (Karlsson et al., } \\
\text { 2012) }\end{array}$ \\
\hline Human & $16 S$ sequencing & Clostridium, Faecalibacterium & Prevotella & $\begin{array}{l}\text { (Gozd- } \\
\text { Barszczewska } \\
\text { et al., 2017) }\end{array}$ \\
\hline Mice & $16 S$ sequencing & Roseburia & & $\begin{array}{l}\text { (Kasahara et al., } \\
\text { 2018) }\end{array}$ \\
\hline Human & $16 \mathrm{~S}$ sequencing & $\begin{array}{l}\text { Burkholderia, Corynebacterium and } \\
\text { Sediminibacterium, unclassified } \\
\text { Comamonadaceae, Oxalobacteraceae, } \\
\text { Rhodospirillaceae, Bradyrhizobiaceae and } \\
\text { Burkholderiaceae }\end{array}$ & $\begin{array}{l}\text { Curvibacter, unclassified } \\
\text { Burkholderiales, } \\
\text { Propionibacterium, } \\
\text { Ralstonia }\end{array}$ & $\begin{array}{l}\text { (Ziganshina } \\
\text { et al., 2016) }\end{array}$ \\
\hline \multicolumn{5}{|c|}{ Hypertension } \\
\hline Rat & $16 S$ sequencing & Family Veillonellaceae & $\begin{array}{l}\text { Plasma acetate and } \\
\text { heptanoate }\end{array}$ & $\begin{array}{l}\text { (Mell et al., } \\
\text { 2015) }\end{array}$ \\
\hline Human & $\begin{array}{r}\text { Metagenomic } \\
\text { sequencing }\end{array}$ & & Prevotella and Klebsiella & (Li et al., 2017a) \\
\hline Human & $\begin{array}{r}\text { Metagenomic } \\
\text { sequencing }\end{array}$ & Roseburia spp., Faecalibacterium prausnitzii, & $\begin{array}{l}\text { Klebsiella spp., } \\
\text { Streptococcus spp., } \\
\text { and Parabacteroides } \\
\text { merdae }\end{array}$ & (Yan et al., 2017) \\
\hline Human & $16 \mathrm{~S}$ sequencing & Butyrate-producing bacteria Odoribacter & & $\begin{array}{l}\text { (Gomez-Arango } \\
\text { et al., 2016) }\end{array}$ \\
\hline \multicolumn{5}{|c|}{ Heart failure } \\
\hline Human & $16 S$ sequencing & $\begin{array}{l}\text { Blautia, Collinsella, uncl. Erysipelotrichaceae } \\
\text { and uncl. Ruminococcaceae }\end{array}$ & & $\begin{array}{l}\text { (Luedde et al., } \\
\text { 2017) }\end{array}$ \\
\hline Human & $\begin{array}{l}\text { Incubation with a } \\
\text { selective agar }\end{array}$ & & $\begin{array}{l}\text { Campylobacter, Shigella, } \\
\text { Salmonella, Yersinia } \\
\text { Enterocolitica, }\end{array}$ & $\begin{array}{l}\text { (Pasini et al., } \\
\text { 2016) }\end{array}$ \\
\hline Human & 16S sequencing & Faecalibacterium & Lactobacillus & $\begin{array}{l}\text { (Kamo et al., } \\
\text { 2017) }\end{array}$ \\
\hline Human & $\begin{array}{r}\text { Metagenomic } \\
\text { sequencing }\end{array}$ & Faecalibacterium prausnitzii & Ruminococcus gnavus & (Cui et al., 2018) \\
\hline \multicolumn{5}{|c|}{ Atrial fibrillation } \\
\hline Human & $\begin{array}{r}\text { Metagenomic } \\
\text { sequencing }\end{array}$ & $\begin{array}{l}\text { Faecalibacterium, Alistipes, Oscillibacter, and } \\
\text { Bilophila }\end{array}$ & $\begin{array}{l}\text { Ruminococcus, } \\
\text { Streptococcus, and } \\
\text { Enterococcus, }\end{array}$ & $\begin{array}{l}\text { (Zuo et al., } \\
\text { 2019a) }\end{array}$ \\
\hline
\end{tabular}

lead to hypertensive gut pathological changes (Santisteban et al., 2017). Results from these studies have associated the gut microbiota with the development of hypertension although the mechanisms of how they function remain elusive.
Heart failure (HF)

$\mathrm{HF}$, a disease characterized by a reduced ability of the heart to pump enough blood and oxygen to meet the body's needs, is often the end clinical stage of many CVDs. Altered microbial composition has been reported in patients with HF 
(Luedde et al., 2017). HF-related multisystem disorder often display impaired intestinal barrier functions, this may lead to enhanced interaction between the intestinal microtiota with the host intestinal mucosa. Consequently, this may result in increased circulating lipopolysaccharides levels and the activation of downstream inflammatory responses (Sandek et al., 2007; Sandek et al., 2012). Furthermore, patients with comorbid HF are reported to experience Clostridium difficile infection (CDI) more frequently (Mamic et al., 2016).

Sequencing studies on HF cohorts consistently found reduced microbial diversity and depletion of several butyrate producing microorganisms. Enhanced populations of pathogenic Campylobacter, Shigella and Salmonella bacteria as well as less abundant Eubacterium rectale and Dorea longicatena bacteria were isolated from fecal samples of $\mathrm{HF}$ patients (Kamo et al., 2017; Pasini et al., 2016). In addition, certain HF patients with highly reduced left ventricular ejection fractions showed significant reductions in Blautia, Collinsella, unidentified Erysipelotrichaceae and Ruminococcaceae spp. populations (Luedde et al., 2017). Chronic HF (CHF) patients demonstrated reduced Faecalibacterium prausnitzii and increased Ruminococcus gnavus populations (Cui et al., 2018). The microbiota also varies according to age. Compared with younger patients, older HF patients is usually devoid the Faecalibacterium genus and enrichment of Lactobacillus species (Kamo et al., 2017).

\section{Atrial fibrillation}

Specific perturbations and disorder of gut microbesin fecal samples have been observed to accompany atrial fibrillation, one of the most prevalent and widespread arrhythmias. It has been reported that overgrowth of Ruminococcus, Streptococcus and Enterococcus, together with reductions in Faecalibacterium, Alistipes, Oscillibacter and Bilophila occur in atrial fibrillation patients (Zuo et al., 2019a). The gut microtiota in both patients with persistent atrial fibrillation is significantly perturbed with elevated microbial diversity, distinct structures, and discrepant (Zuo et al., 2019b).

\section{Changes in blood microbial composition}

Blood is traditionally considered to be a sterile environment devoid of any microorganisms under most healthy conditions. However, increasing evidence suggests the existence of blood microbiome. The blood microbiota of healthy humans is dominated by Proteobacteria, while the gut microbiota is predominantly composed of the bacterial phyla Firmicutes and Bacteroidetes (Castillo et al., 2019). The major route by which microbes enters the blood is thought to be through translocation from microbe-enriched organs (such as the gut) or via prenatal migration.

Circulating microbes may act as prime sources for microbial colonization of atherosclerotic plaques and subsequent development of inflammation and CVDs. CVD patients showed elevated concentrations of circulating microbes, with significantly elevated Proteobacteria and Pseudomonadaceae populations and decreased Firmicutes Gammaproteobacteria, Bacillales and Staphylococcaceae abundance (Dinakaran et al., 2014; Rajendhran et al., 2013). Increased levels of Staphylococcus spp. was found in the circulating blood in congenital heart disease (CHD), valvular heart disease (VHD), and ischemic heart disease (IHD) (Dinakaran et al., 2012). It has been reported that the cardiovascular outcomes of ST-segment elevation myocardial infarction (STEMI) patients are driven by intestinal microbe translocation into the systemic circulation. Increased abundances of Lactobacillus, Bacteroides and Streptococcus were detected in these STEMI patients, possibly as a result of tight junction disruptions in the gut barrier (Zhou et al., 2018). These changes in circulating microbes may induce chronic infection and inflammatory responses, leading to CVDs.

\section{Changes in microbial metabolites}

There are a number of intestinal microbial metabolites, such as vitamins, hormones, SCFAs, amino acid derivatives and antioxidants in the gut (Sekirov et al., 2010). These metabolites may be directly absorbed and enter the host circulation to migrate to distant organs. Alternatively, they maybe metabolized by host enzymes to serve as signaling molecules. The majority of microbe generated metabolites can exert synergistic effects in healthy individuals (Fig. 1).

\section{Short chain fatty acids (SCFA)}

Human gut is incapable of digesting complex carbohydrates in the form of dietary fiber for cell activities. However, the gut microbiota is able to utilize fibers through the fermentation process, leading to the production of SCFAs (Ahmad et al., 2019). SCFAs are saturated fatty acids that contain one to six carbon chains. Acetate, propionate and butyrate account for the majority of SCFAs in human body (Blacher et al., 2017). SCFAs serve as key regulators of anti-inflammatory responses as well as lipid metabolic pathways and gluconeogenesis. In addition, these molecules, in particular the butyrate, are viewed as energy substrates for epithelial cells of the intestines (Donohoe et al., 2011).

It is thought that SCFAs in the systemic circulation mediate the potential modulatory effects of the microbiota on CVDs. Numerous studies indicated that sodium butyrate and propionate produced by the gut microbiota are inversely correlated with the function of prorenin receptor-mediated intrarenal rennin-angiotensin system and contribute to lower blood pressure (Pluznick et al., 2013; Wang et al., 2017). Functionally, SCFAs absorbed into the bloodstream may mediate blood pressure effectors via the $G$ protein-coupled receptors (GPCRs), such as Olfactory receptors 78 (Olfr78) and $G$ protein-coupled receptor 41 (GPR41). Both receptors are localized in small resistance vessels, where they act divergently towards vascular tone. Under stimulation by 


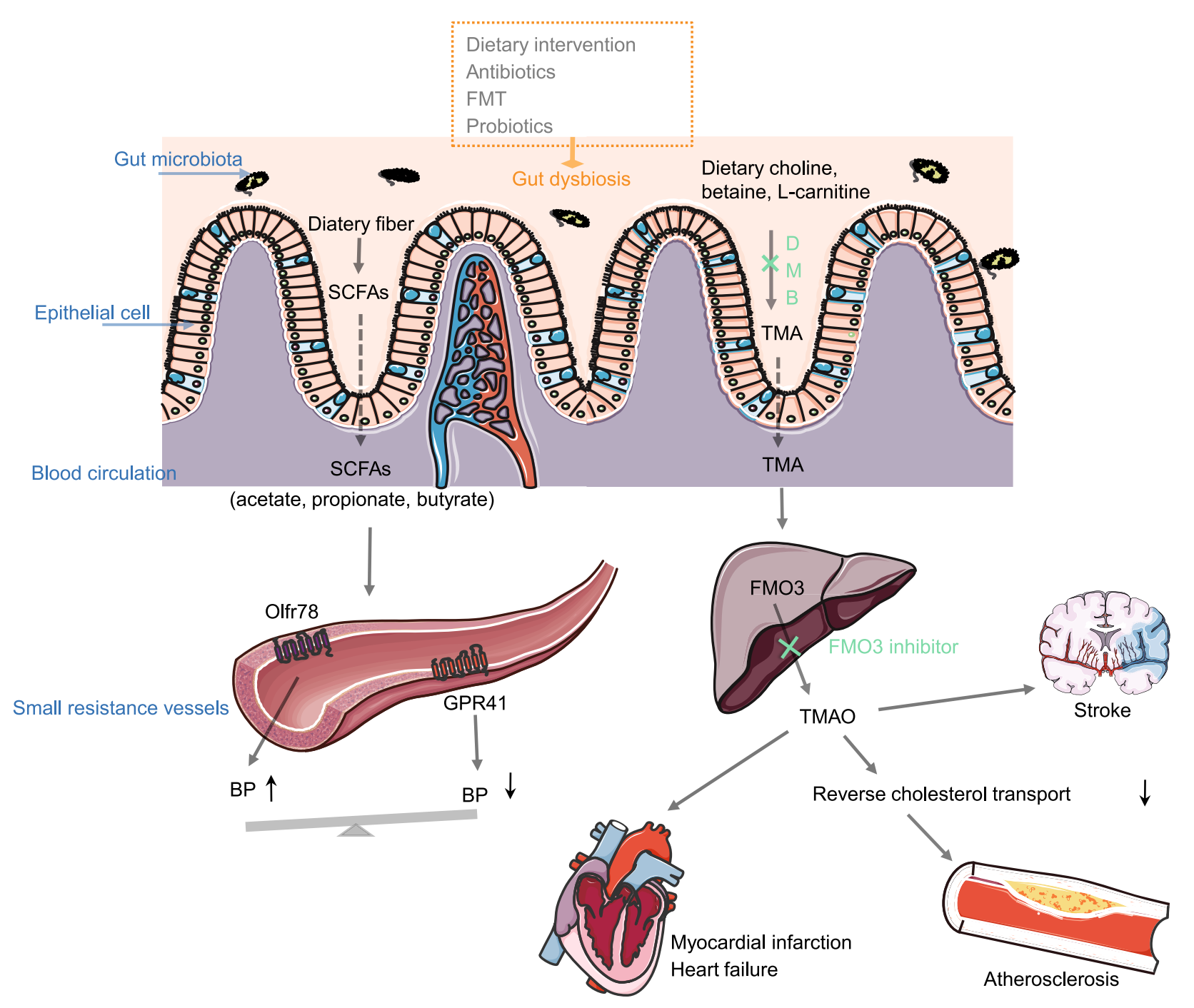

Figure 1. Microbiota-associated metabolites involved into the pathogenesis of CVDs. Nutrition can be metabolized to TMA by gut microbiota, which is inhibited by DMB. Most of TMA is absorbed into circulation and converted into TMAO by hepatic FMO3 (flavin monooxygenases). The circulaing TMAO may be indicators of MI, HF, peripheral artery disease, etc. Some intestianl microflora metabolite, such as SCFAs, can regulate blood pressure by combining with Olfr78 and GPR41. Microbiota-targeted therapeutics can alter the dysbiosis of gut microbiota.

SCFAs, GPR41 acts as a hypotensive protein to dilate resistance vessels in an endothelium-dependent manner. This hypotensive effect can be neutralized by Olfr78 (Natarajan et al., 2016). These two receptors provide the necessary functional balance to prevent excessive variation in blood pressures under healthy conditions (Pluznick, 2014). In addition, it has been reported that microbiotaderived SCFAs play an immunomodulatory role in oxidative stress attenuation and functional immune system maintenance. Dietary supplementation with $1 \%$ butyrate has been shown to slow atherosclerosis progression through its antiinflammatory function and enhanced plaque stability (Aguilar et al., 2014). Moreover, SCFA propionate protects against cardiac hypertrophy, fibrosis, vascular dysfunction, and hypertension in a T cell-dependent manner (Bartolomaeus et al., 2019).

\section{Trimethylamine N-oxide (TMAO)}

Among the microbial metabolites, TMAO has gained considerable attention as a major contributing factor in CVDs. TMAO is a hepatic oxidation product of trimethylamine (TMA), which is primarily derived from bacterial metabolism of dietary choline and phosphatidylcholine (Wang et al., 2011). Studies on germ-free mice and human cohorts have indicated a positive linkage between plasma TMAO levels and increased CVD risk (Koeth et al., 2013; Tang et al., 
2013; Tang et al., 2015; Wang et al., 2011; Wang et al., 2014). Mice fed with choline-rich and carnitine-rich diets showed elevated plasma TMAO levels and atherosclerotic plaque enhancement, while diet supplement depletion or intestinal microbiota suppression can eliminate TMAO generation and reduce atherosclerosis (Koeth et al., 2013; Wang et al., 2011). Thus, circulating TMAO may be a useful indicator for CVD diagnosis. Elevated TMAO levels may suggest increased risks for developing myocardial infarction (MI) (Li et al., 2017b), HF (Tang et al., 2014), peripheral artery disease (Senthong et al., 2016a), stroke (Tang et al., 2013; Wang et al., 2014) as well as stable coronary artery disease (Senthong et al., 2016b), independent of the traditional cardiac risk factors (Tang et al., 2013). Individuals taking broadspectrum antibiotics result in depleted gut microbiota and show significant drops in TMAO levels (Tang et al., 2013; Wang et al., 2014). In addition, since diet is a major source of TMAO, individuals are suggested to avoid excessive consumption of foods rich in carnitine, choline and lecithin (Koeth et al., 2013) to reduce the risk of developing CVD.

Koeth et al. found that the presence of TMAO is associated with changes in plasma lipid, cholesterol and sterol metabolism (Koeth et al., 2013). In vitro and in vivo experimental evidences have revealed contributory mechanisms of TMAO on the vascular dysfunction, inflammatory responses and oxidative stress (Brunt et al., 2020; Seldin et al., 2016). The endoplasmic reticulum stress kinase PERK has been identified as a TMAO receptor (Chen et al., 2019). Interestingly, TMAO has been reported to play a protective role in hemodialysis patients with vascular injury, partly due to its inhibitory actions on AGE (Fukami et al., 2015).

Several choline analogues have been reported to reduce TMAO levels in the circulation. A natural compound 3,3dimethyl-1-butanol (DMB), exists widely in vinegars, red wines and some grape seed oils, has been found to inhibit the microbial choline TMA lyase activity. This compound could inhibit atherosclerotic lesion development in $\mathrm{Apoe}^{-/-}$ mice without alterations in circulating cholesterol levels (Wang et al., 2015). Other choline analogues, such as fluromethylcholine (FMC), chloromethylcholine, bromomethylcholine, iodomethylcholine (IMC), are reported to be more potent TMA lyase inhibitors to lower plasma TMAO levels (Roberts et al., 2018).

\section{Other metabolites}

Phenylalanine (Phe), tryptophan (Trp) and tyrosine (Tyr) are aromatic amino acids that may influence immune, metabolic, and neuronal responses. Phe, an essential amino acid, is a metabolic precursor for Tyr, which maybe further processed into neurotransmitters, norepinephrine and adrenaline. Trp, also an essential amino acid, is a precursor for serotonin, another neurotransmitter. In patients with advanced atherosclerosis, the specific microbe-derived metabolite of Trp was significantly lower in plasma (Cason et al., 2018). A recent study showed that the gut microbiota metabolites of
Tyr and Phe may be related to the severity of MI in rats (Lam et al., 2016). Further step into the mechanistic links between these aromatic amino acids metabolites and cardiovascular diseases is needed.

Phenylacetylglutamine (PAGIn), which is produced as the dietary Phe converted into phenylacetic acid, has been reported to be associated with CVDs and major adverse cardiovascular events (Poesen et al., 2016). This gut microbiota-derived metabolite acts to enhance platelet activation-related phenotypes and thrombosis potential, signaling through adrenergic receptors (Nemet et al., 2020).

\section{Gaps in knowledge}

Recent studies have highlighted the potential roles of microbiome dysbiosis in CVD diseases. Advances in genomic and metabolomics approaches have facilitated more in depth characterization and mechanistic exploration of these microbiome and their metabolites. However, most data are still making correlations and the exact molecular mechanisms underlying most observed phenomena remain unknown. Future studies focusing on microbe-microbe and microbe-host interactions may unravel how certain metabolic molecules function to modulate the disease process. It is also of great importance to understand more deeply on microbial pathways involved into the biosynthesis of CVD related metabolites, and the functional roles of these metabolites (Wang and Zhao, 2018). Results from these studies may provide essential scientific basis for the development of therapeutic interventions to prevent and treat CVD patients.

\section{MICROBIOTA-TARGETED THERAPEUTICS}

Increasing evidence indicate that gut microbiota play an important role in the progression of CVDs. Thus, gut microbiota has emerged as an ideal target for disease prevention and treatment. Therapeutic strategies designed to manipulate gut microbiota composition and/or their metabolisms have been developed, including dietary intervention; probiotic, prebiotic, and antibiotic treatments; as well as fecal transplantation (Fig. 2). These strategies have improved blood pressure levels, normalized lipid profiles, and reduced body weight in some CVD patients.

\section{Dietary intervention}

Dietary intervention has been widely practiced to alleviate chronic conditions. For example, heart-healthy diets rich in vegetables and high in fibers is thought to be beneficial to the cardiovascular system (De Filippis et al., 2016). Consumption of mediterranean diet and dietary approaches to stop hypertension (DASH) diet (rich in fruits, vegetables, legumes, and unsaturated fats with limited red meat intake) has been thought to reduce CVD incidence among participants with high cardiovascular risk (Appel et al., 1997). 


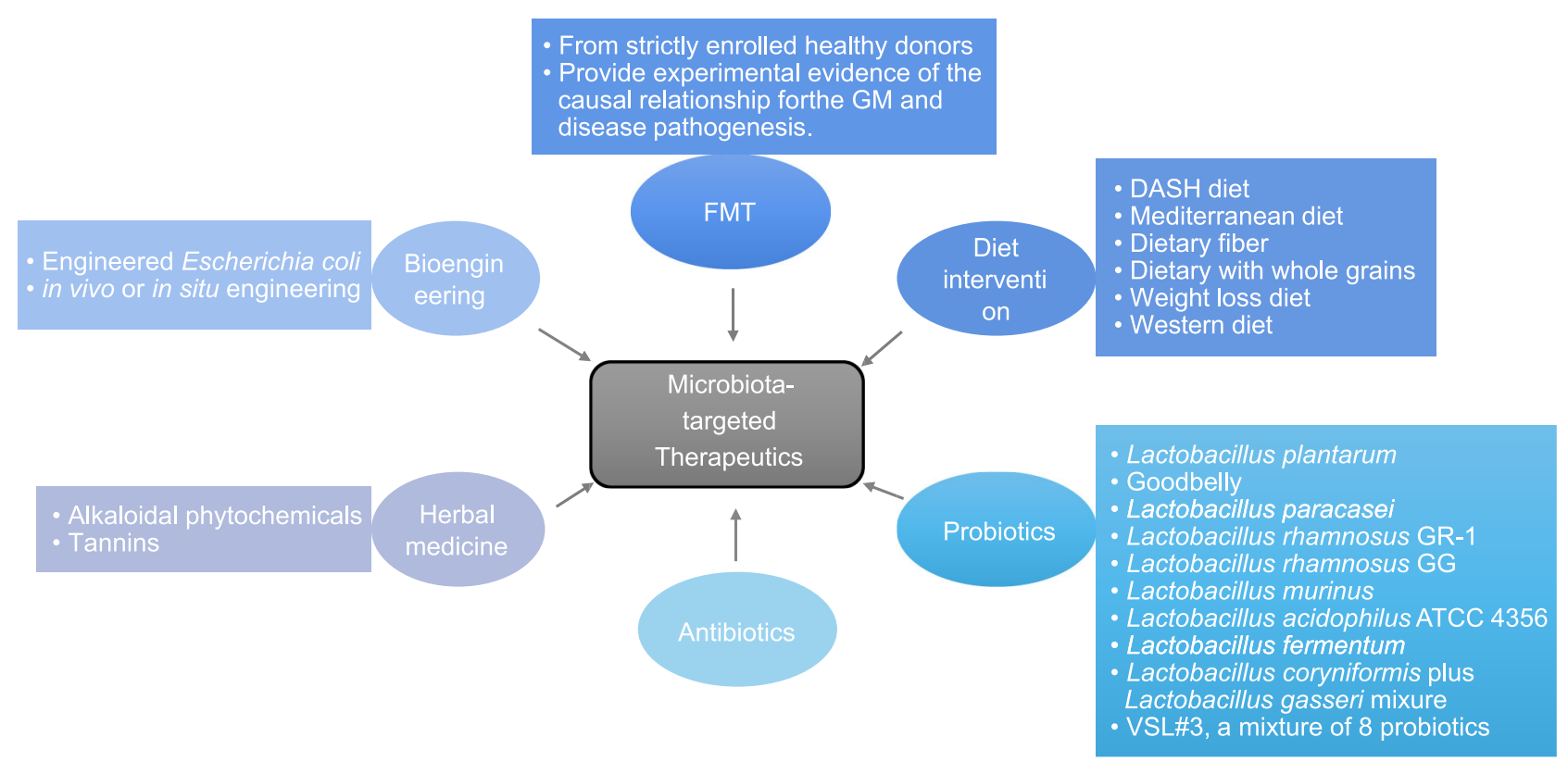

Figure 2. Potential interventions associated with gut microbiota correction and CVDs improvement. There are six strategies discussed in the present review, including dietary interventions, probiotics, antibiotics, FMT, bioengineering, and herbal medicine.

It is widely accepted that dietary habits influence the composition and function of gut microbiota, thus modulate human health via digestion and absorption of various nutrients. These health effects can persist throughout an individual's lifespan (David et al., 2014; Xu and Knight, 2015). For example, dietary fiber may alter the host microbiota compositions. Mice treated with excess mineralocorticoids and fed a high-fiber diet demonstrate increased abundance of the acetate-producing bacterium Bacteroides acidifaciens, down-regulation of a master cardiovascular regulator gene, and improved cardiovascular health and function (Marques et al., 2017). An intake of lower dietary fiber is associated with reduced microbial diversity and SCFA production but higher production of metabolites that are potentially detrimental to mucins. It is speculated that dietary fiber deprivation-induced degradation of the colonic mucus barrier is responsible for the enhanced susceptibility to infections (Desai et al., 2016). Mediterranean diet consumers exhibit reduced CVD incidence and elevated levels of fecal SCFAsand fiber-degrading Firmicutes (Trichopoulou et al., 2009). A dietary scheme with more whole grains resulted in improvements in lipid profiles and blood pressure accompanied by concomitant reductions in opportunistic pathogens of the Enterobacteriaceae family and increases in gut barrier-protecting Bifidobacteriaceae bacteria (Xiao et al., 2014). A weight-loss diet consisting high intake of proteins but low fermentable carbohydrates improved the abundance of butyrate-producing Roseburia bacteria and Eubacterium rectale (Duncan et al., 2007). However, a Western diet rich in saturated fats and sugars and low in fiber is known to be associated with increased CVD risk. This diet reduces microbial diversity, decreases the levels of beneficial Bifidobacterium and Eubacterium bacterial population, increases the abundance of the mucin-degrading bacterium Akkermansia muciniphila, and promote T helper 17 (TH17) cell activity (Battson et al., 2018b; Wilck et al., 2017).

Diet interventions are relatively low cost and easily to administer for CVDs prevention and treatment. However, microbiome-based dietary approach may result in unintended consequences. For example, microbe-generated metabolites may act on multiple tissues and targets. The mechanisms remain unclear for most of the effects of dietary interventions (Turnbaugh, 2020). Due to the enormous heterogeneity in gut microbial composition and their functions, more personalized diets may be needed instead of a universal diet. In addition to food composition, cooking methods and the broad chemical diversity of plants further complicates the interplay between microbiota and CVDs.

\section{Antibiotics}

Microbiota can be modulated with antibiotics and has been utilized to restore microbial communities and prevent CVDs. In one study, a 69-year patient with a long history (44 years) of hypertension and resistance hypertension showed lower blood pressure after combined antibiotic treatment (Qi et al., 2015). Separately, two months of dietary intervention with a broad-spectrum antibiotic cocktail reversed Western diet induced vascular dysfunction, which is a critical preclinical step in CVD progression (Battson et al., 2018a). Furthermore, vancomycin usage is associated with decreased myocardial infarct area (27\% reduction) and improved post 
ischemic recovery of mechanical function (35\%) along with effective reductions in the total numbers and groups of intestinal microbes (Lam et al., 2012).

Although antibiotics are commonly used against pathogens, they are non-discriminatory between pathogens and commensal microorganisms. Thus, antibiotic therapy may worsen the emergence of antibiotic-resistant bacteria. Consequently, consumption of antibiotics may lead to microbiota dysbiosis and anti-microbial resistance. In a meta-analysis of 33 studies including 20,779,963 participants, macrolide antibiotic administration was found to be associated with increased risk of sudden cardiac death (SCD) or ventricular tachyarrhythmia (VTA) (Cheng et al., 2015). Future studies are urgently needed to optimize the application of antibiotics in VCD-related patients.

\section{Probiotics}

Probiotics contain beneficial bacteria intended to establish normal intestinal microbiome balance. One meta-analysis of clinical trials found that probiotic treatment may be effective in lowering total and low density lipoprotein (LDL) cholesterol levels, improving blood pressures, and in modulating inflammatory cytokines (Khalesi et al., 2014; Shimizu et al., 2015; Xue et al., 2017). Bifidobacterium spp. and Lactobacillus spp. are used widely and maybe the most promising probiotic species (Azad et al., 2018).

Lactobacillus plantarum is a probiotic supplement in the form of fermented plant foods (Molin, 2001). Rats fed with Lactobacillus plantarum showed reduced bacterial translocation, less mucosal inflammatory responses and increased abundances of the genera Escherichia and Salmonella. Dietary intake of Lactobacillus plantarum lowered serum levels of leptin and fibrinogen, two CVD risk factors, resulting in lower atherosclerosis in smokers (Naruszewicz et al., 2002). Among men with arteriosclerosis, consumption of drinks with high content of Lactobacillus plantarum increased the diversity of beneficial bacteria (Karlsson et al., 2010). Similarly, intake of Good belly (containing the strains Lactobacillus plantarum $299 \mathrm{v}$ and Bifidobacterium lactis Bi07) significantly reduced the infarct size and improve left ventricular function after MI (Lam et al., 2012).

Lactobacillus paracasei and Lactobacillus rhamnosus are enriched in dairy products (Molin, 2001). Consumption of Lactobacillus rhamnosus GR-1 contributes to the attenuation of left ventricular hypertrophy and improvement of systolic and diastolic left ventricular function after MI (Gan et al., 2014). Intervention with Lactobacillus rhamnosus GG can ameliorate atherosclerosis in a $\mathrm{GM}$-associated manner (Chan et al., 2016a).

Probiotics with other Lactobacillus spp. also known to have positive effects on CVDs. Lactobacillus murinus-treated mice demonstrated resistance to high salt-induced hypertension due to the inhibition of TH17 cells (Wilck et al., 2017). Lactobacillus acidophilus ATCC 4356 prevents atherosclerosis by inhibiting intestinal cholesterol absorption in ApoE(-l-) mice (Huang et al., 2014). Probiotic mixtures of Lactobacillus fermentumor, Lactobacillu scoryniformis, and Lactobacillus gasseri had cardiovascular protective effects in hypertensive rats. This is possibly due to improvements in vascular pro-oxidative and proinflammatory status. Changes in the cecal microbiota with increases in Lactobacillus spp. and decreases in Bacteroides spp. and Clostridium spp. may also contributed to the protective effects (Gomez-Guzman et al., 2015). VSL\#3 is a mixture consists of 8 probiotics with anti-inflammatory potential. It has been shown that VSL\#3 reduced the risk for atherosclerotic plaque rupture and vascular inflammation, as well as improved dyslipidemia profiles in overweight adults (Chan et al., 2016b; Lopez-Mejias et al., 2014; Mencarelli et al., 2012).

The benefits of relevant probiotics remain controversial. Animal model studies and human clinical trials revealed no beneficial effects of probiotics on CVDs (Fak and Backhed, 2012; Portugal et al., 2006; Vaghef-Mehrabany et al., 2017). These discrepancies may be partly due to differences in the probiotic strains or doses consumption, the experimental variation, and the heterogeneity of participants. As of today, most probiotic studies focused on populations with specific health issues, the general effect of probiotic consumption in healthy individuals requires further investigation (Khalesi et al., 2019).

\section{Fecal microbiota transplantation}

Fecal microbiota transplantation (FMT) is a therapeutic strategy designed to transfer donor fecal samples into the gastrointestinal $(\mathrm{GI})$ tract of a patient with a depleted microbiota, for the aim of restoring normal GI microbiota in patients. Depending on the source of the fecal microbiota for transplantation, FMT can be divided into allogenetic FMT (fecal material from a healthy donor) and autologous FMT (patients receive their own fecal material). Allogenic FMT are the most commonly used (Halkjaer et al., 2018). The fecal microbiota can be prepared in a lab for transplantation in four different ways: rough filtration, filtration plus centrifugation (FPC), microfiltration plus centrifugation (MPC), and purification. All these methods aim to minimize the processing time to minimize the loss of living bacteria (Zhang et al., 2018). FMT delivery routes include the upper gut, middle gut and lower gut. Microbiota capsules are delivered through the upper gut, while microbiota suspensions can be infused into the lower gut through colonic transendoscopic enteral tubing (TET) (Zhang et al., 2019).

The FMT approach has generated great interest when treating intestinal diseases, such as Clostridium difficile infection and inflammatory bowel diseases. Evidence suggests that FMT is markedly superior to antibiotic therapy in treating recurrent Clostridium difficile infection (van Nood et al., 2013). Recently, this strategy has also been successfully applied to patients with cardiometabolic disorders (Vrieze et al., 2012). Interestingly, obese patients with metabolic syndrome show enhanced insulin sensitivity when first infused with intestinal microbes from lean donors. 
Successful FMT also provides solid evidence underlying the direct role of gut microbiota in disease pathogenesis. In those studies, fecal microbiota from healthy and pathological individuals was transplanted into germ-free (GF) rodents, and the recipient animals were analyzed for pathological changes (Maruvada et al., 2017). Majority of recipient rodents are reported to develop pathological phenotypes after fecal transplantation, however, some of them have commonly used small numbers of disease donors and conducted replication in larger numbers of individual mice (Walter et al., 2020). In addition, a substantial proportion of taxa in the human gut microbiota failed to colonize the recipient animals, suggesting unknown ecological factors may be absent in recipient rodents to facilitate human gut microbiota growth. Therefore, disease-associated alterations in humans are complex and difficult to replicate in animals such as rodents.

Despite the successful application of FMT in some patients, careful additional evaluations must be carried out before it can be widely implemented. First, FMT treatment alters levels of both harmful and beneficial bacteria, thus, adverse effects could be potentially induced into the recipient. Second, microbiome is diverse throughout the digestive tract, and it is important to obtain the most representative donor samples possible. Third, the potential transfer of endotoxins or infectious agents through FMT may lead to new GI complications. Fourth, a number of ethical issues further complicate FMT. In addition, informed consent, the availability of suitable healthy donors, safety and risk, remain to be carefully considered for all patients. Safe guard has to be established to monitor the FMT procedure and to protect both the patients and donors. These practices will promote further research into FMT and prevent abuse.

\section{Bioengineering}

Bacteria are well suited to be genetically modified to have desired properties, such as a particular metabolic activity and produce a specific end product. Thus, it is possible to engineer the bacteria to possess more beneficial effects (Lam et al., 2019). Strains of Escherichia coli engineered to express particular genes that can alleviate rare metabolic diseases are now in clinical trials. For example, the SYNB1618 strain of Escherichia coli has been engineered to express proteins that are capable of degrading Phe, which is responsible for causing human phenylketonuria (PKU) disease (Isabella et al., 2018). To take one step further, in vivo and in situ engineering approaches, which are performed in the host rather than in the laboratory, have been described (Ronda et al., 2019).These genetic tools and the resulting microbial tools have ushered in an era of precision medicine treating the GM disorders.

\section{Herbal medicines}

Herbal medicines are plant-derived materials that are mostly orally administered and are known to be effective in long- term clinical practice (Cheung, 2011). Although research on the effects of herbal medicines on the gut microbiota is still in its infancy, initial findings are encouraging the use of these medicines to help to treat gut microbiota-related illnesses.

Rhizoma coptidis $(\mathrm{RC})$ is the dried rhizome of a medicinal plant from the family Ranunculaceae and contains alkaloids such as berberine, coptisine, and palmatine (He et al., 2016). Feeding of RC alkaloids to hyperlipidemic mice significantly changed the gut microbiota with increased abundance of Akkermansia muciniphila, Sporobacter termitidis and Alcaligenes faecalis while suppressing the abundances of Parabacteroides distasonis and Escherichia coli. Barbering-treated rats with high-fat diet (HFD)-induced hyperlipidemia exhibit reduced Escherichia populations and increased levels of beneficial bacteria (e.g., Bacteroides and Blautia) (Li et al., 2016). Alkaloid phytochemicals modulate both the gut microbiota and the bile acid pathway to reduce levels of triglycerides, total serum cholesterol, LDL cholesterol, lipopolysaccharide, and total bile acids in mice (Wu and Tan, 2019).

Persimmon tannin (PT) is a type of condensed tannin highly polymerized and non-absorbed in the intestine. It was reported to modify the intestinal bacterial microbiota composition by directly interacting with the colonic gut microbial ecosystem (Ozdal et al., 2016). The anti-hyperlipidemic and cholesterol-lowering effects of this compound on high-cholesterol diets fed SD rats was partly mediated by altered gut microbiota composition, such as increases in Lactobacillus spp. and Bifidobacterium spp. as well as reductions in Escherichia coli and Enterococcus populations (Zhu et al., 2018).

\section{FUTURE PERSPECTIVES}

Increasing evidence suggest a link between the intestinal microbiome and CVD incidence. Studies have indicated that the microbiota interacts with the host through multiple pathways. Abnormal gut microbiota composition or microbial metabolites may be responsible for altering CVDs risks and its related pathological changes. Thus, novel therapeutic targets/strategies for preventing and treating CVD have been developed harnessing the potential use of gut microbiota.

Intense efforts are underway to advance the potential use of microbiota in CVD and other human diseases in general. First, identification of specific microbe strains rather than a general bacterial community is helpful to elucidate the contributions of specific microorganisms to disease progression. Second, future research may focus more on microbiomemediated metabolites and their downstream functional consequences, while the current studies mostly explore the microbial composition. Third, personalized approaches for microbiota modification are urgently needed. This effort may be aided by microbiome profiling of individual patients for their metabolomic biomarker. 


\section{ACKNOWLEDGEMENTS}

This work is supported by the National Key R\&D Program of China (Project ID. 2018YFC1312703), CAMS Innovation Fund for Medical Sciences (2016-I2M-1-006), National Natural Science Foundation of China (81630014, 81700374, 81825002, 91749107), Beijing Outstanding Young Scientist Program (BJJWZYJH01201910023029) and Interdisciplinary Medicine Seed Fund of Peking University (BMU2020MX021).

\section{ABBREVIATIONS}

$\mathrm{CDI}$, clostridium difficile infection; $\mathrm{CHD}$, congenital heart disease; CVDs, cardiovascular diseases; DASH, dietary approaches to stop hypertension; DMB, 3,3-dimethyl-1-butanol; FMC, fluromethylcholine; FMT, fecal microbiota transplantation; GF, germ-free; GI, gastrointestinal; GM, gut microbiota; GPCRs, G protein-coupled receptors; GPR41, G protein-coupled receptor 41; HF, heart failure; IHD, ischemic heart disease; IMC, iodomethylcholine; LDL, Iow density lipoprotein; MI, myocardial infarction; Olfr78, olfactory receptors 78; PAGIn, phenylacetylglutamine; Phe, phenylalanine; $\mathrm{PT}$, persimmon tannin; RC, rhizoma coptidis; $S C D$, sudden cardiac death; SCFA, short chain fatty acid; STEMI, ST-segment elevation myocardial infarction; TET, transendoscopic enteral tubing; TH17, T helper 17; TMA, trimethylamine; TMAO, trimethylamine $\mathrm{N}$-Oxide; Trp, tryptophan; Tyr, tyrosine; VHD, valvular heart disease; VTA, ventricular tachyarrhythmia.

\section{COMPLIANCE WITH ETHICS GUIDELINES}

Ling Jin, Xiaoming Shi, Jing Yang, Yangyu Zhao, Lixiang Xue, Li Xu and Jun Cai declare that they have no conflict of interest. This article does not contain any studies with human or animal subjects performed by the any of the authors.

\section{OPEN ACCESS}

This article is licensed under a Creative Commons Attribution 4.0 International License, which permits use, sharing, adaptation, distribution and reproduction in any medium or format, as long as you give appropriate credit to the original author(s) and the source, provide a link to the Creative Commons licence, and indicate if changes were made. The images or other third party material in this article are included in the article's Creative Commons licence, unless indicated otherwise in a credit line to the material. If material is not included in the article's Creative Commons licence and your intended use is not permitted by statutory regulation or exceeds the permitted use, you will need to obtain permission directly from the copyright holder. To view a copy of this licence, visit http:// creativecommons.org/licenses/by/4.0/.

\section{REFERENCES}

Adnan S, Nelson JW, Ajami NJ, Venna VR, Petrosino JF, Bryan RM Jr, Durgan DJ (2017) Alterations in the gut microbiota can elicit hypertension in rats. Physiol Genomics 49:96-104
Aguilar EC, Leonel AJ, Teixeira LG, Silva AR, Silva JF, Pelaez JM, Capettini LS, Lemos VS, Santos RA, Alvarez-Leite JI (2014) Butyrate impairs atherogenesis by reducing plaque inflammation and vulnerability and decreasing NFkappaB activation. Nutr Metab Cardiovasc Dis 24:606-613

Ahmad AF, Dwivedi G, O'Gara F, Caparros-Martin J, Ward NC (2019) The gut microbiome and cardiovascular disease: current knowledge and clinical potential. Am J Physiol Heart Circ Physiol 317:H923-H938

Appel LJ, Moore TJ, Obarzanek E, Vollmer WM, Svetkey LP, Sacks FM, Bray GA, Vogt TM, Cutler JA, Windhauser MM et al (1997) A clinical trial of the effects of dietary patterns on blood pressure. DASH Collaborative Research Group. N Engl J Med 336:11171124

Azad MAK, Sarker M, Li T, Yin J (2018) Probiotic species in the modulation of gut microbiota: an overview. Biomed Res Int 2018:9478630

Bartolomaeus H, Balogh A, Yakoub M, Homann S, Marko L, Hoges S, Tsvetkov D, Krannich A, Wundersitz S, Avery EG et al (2019) Short-chain fatty acid propionate protects from hypertensive cardiovascular damage. Circulation 139:1407-1421

Battson ML, Lee DM, Jarrell DK, Hou S, Ecton KE, Weir TL, Gentile CL (2018a) Suppression of gut dysbiosis reverses Western dietinduced vascular dysfunction. Am J Physiol Endocrinol Metab 314:E468-E477

Battson ML, Lee DM, Weir TL, Gentile CL (2018b) The gut microbiota as a novel regulator of cardiovascular function and disease. J Nutr Biochem 56:1-15

Blacher E, Levy M, Tatirovsky E, Elinav E (2017) Microbiomemodulated metabolites at the interface of host immunity. J Immunol 198:572-580

Brunt VE, Gioscia-Ryan RA, Casso AG, VanDongen NS, Ziemba BP, Sapinsley ZJ, Richey JJ, Zigler MC, Neilson AP, Davy KP et al (2020) Trimethylamine-N-oxide promotes age-related vascular oxidative stress and endothelial dysfunction in mice and healthy humans. Hypertension 76:101-112

Cason CA, Dolan KT, Sharma G, Tao M, Kulkarni R, Helenowski IB, Doane BM, Avram MJ, McDermott MM, Chang EB et al (2018) Plasma microbiome-modulated indole- and phenyl-derived metabolites associate with advanced atherosclerosis and postoperative outcomes. J Vasc Surg 68(1552-1562):e1557

Castillo DJ, Rifkin RF, Cowan DA, Potgieter M (2019) The healthy human blood microbiome: fact or fiction? Front Cell Infect Microbiol 9:148

Chan YK, Brar MS, Kirjavainen PV, Chen Y, Peng J, Li D, Leung FC, El-Nezami H (2016a) High fat diet induced atherosclerosis is accompanied with low colonic bacterial diversity and altered abundances that correlates with plaque size, plasma A-FABP and cholesterol: a pilot study of high fat diet and its intervention with Lactobacillus rhamnosus GG (LGG) or telmisartan in ApoE (-/-) mice. BMC Microbiol 16:264

Chan YK, El-Nezami H, Chen Y, Kinnunen K, Kirjavainen PV (2016b) Probiotic mixture VSL\#3 reduce high fat diet induced vascular inflammation and atherosclerosis in $\mathrm{ApoE}(-/-)$ mice. AMB Express 6:61

Chen S, Henderson A, Petriello MC, Romano KA, Gearing M, Miao J, Schell M, Sandoval-Espinola WJ, Tao J, Sha B et al (2019) 
Trimethylamine $\mathrm{N}$-oxide binds and activates PERK to promote metabolic dysfunction. Cell Metab 30(1141-1151):e1145

Cheng YJ, Nie XY, Chen XM, Lin XX, Tang K, Zeng WT, Mei WY, Liu LJ, Long M, Yao FJ et al (2015) The role of macrolide antibiotics in increasing cardiovascular risk. J Am Coll Cardiol 66:21732184

Cheung F (2011) TCM: made in China. Nature 480:S82-83

Clemente JC, Ursell LK, Parfrey LW, Knight R (2012) The impact of the gut microbiota on human health: an integrative view. Cell 148:1258-1270

Cui X, Ye L, Li J, Jin L, Wang W, Li S, Bao M, Wu S, Li L, Geng B et al (2018) Metagenomic and metabolomic analyses unveil dysbiosis of gut microbiota in chronic heart failure patients. Sci Rep 8:635

David LA, Maurice CF, Carmody RN, Gootenberg DB, Button JE, Wolfe BE, Ling AV, Devlin AS, Varma Y, Fischbach MA et al (2014) Diet rapidly and reproducibly alters the human gut microbiome. Nature 505:559-563

Davignon J, Ganz P (2004) Role of endothelial dysfunction in atherosclerosis. Circulation 109:III27-III32

De Filippis F, Pellegrini N, Vannini L, Jeffery IB, La Storia A, Laghi L, Serrazanetti DI, Di Cagno R, Ferrocino I, Lazzi C et al (2016) High-level adherence to a Mediterranean diet beneficially impacts the gut microbiota and associated metabolome. Gut 65:18121821

Desai MS, Seekatz AM, Koropatkin NM, Kamada N, Hickey CA, Wolter M, Pudlo NA, Kitamoto S, Terrapon N, Muller A et al (2016) A dietary fiber-deprived gut microbiota degrades the colonic mucus barrier and enhances pathogen susceptibility. Cell 167(1339-1353):e1321

Dinakaran V, John L, Rathinavel A, Gunasekaran P, Rajendhran J (2012) Prevalence of bacteria in the circulation of cardiovascular disease patients, Madurai, India. Heart Lung Circ 21:281-283

Dinakaran V, Rathinavel A, Pushpanathan M, Sivakumar R, Gunasekaran P, Rajendhran J (2014) Elevated levels of circulating DNA in cardiovascular disease patients: metagenomic profiling of microbiome in the circulation. PLoS ONE 9:e105221

Donohoe DR, Garge N, Zhang X, Sun W, O'Connell TM, Bunger MK, Bultman SJ (2011) The microbiome and butyrate regulate energy metabolism and autophagy in the mammalian colon. Cell Metab 13:517-526

Duncan SH, Belenguer A, Holtrop G, Johnstone AM, Flint HJ, Lobley GE (2007) Reduced dietary intake of carbohydrates by obese subjects results in decreased concentrations of butyrate and butyrate-producing bacteria in feces. Appl Environ Microbiol 73:1073-1078

Durgan DJ, Ganesh BP, Cope JL, Ajami NJ, Phillips SC, Petrosino JF, Hollister EB, Bryan RM Jr (2016) Role of the gut microbiome in obstructive sleep apnea-induced hypertension. Hypertension 67:469-474

Fak F, Backhed F (2012) Lactobacillus reuteri prevents diet-induced obesity, but not atherosclerosis, in a strain dependent fashion in Apoe-/- mice. PLoS ONE 7:e46837

Franzosa EA, Hsu T, Sirota-Madi A, Shafquat A, Abu-Ali G, Morgan $X C$, Huttenhower C (2015) Sequencing and beyond: integrating molecular 'omics' for microbial community profiling. Nat Rev Microbiol 13:360-372
Fukami K, Yamagishi S, Sakai K, Kaida Y, Yokoro M, Ueda S, Wada Y, Takeuchi M, Shimizu M, Yamazaki H et al (2015) Oral L-carnitine supplementation increases trimethylamine- $\mathrm{N}$-oxide but reduces markers of vascular injury in hemodialysis patients. $J$ Cardiovasc Pharmacol 65:289-295

Gan XT, Ettinger G, Huang CX, Burton JP, Haist JV, Rajapurohitam V, Sidaway JE, Martin G, Gloor GB, Swann JR et al (2014) Probiotic administration attenuates myocardial hypertrophy and heart failure after myocardial infarction in the rat. Circ Heart Fail 7:491-499

Gomez-Arango LF, Barrett HL, McIntyre HD, Callaway LK, Morrison M, Dekker Nitert M, Group ST (2016) Increased systolic and diastolic blood pressure is associated with altered gut microbiota composition and butyrate production in early pregnancy. Hypertension 68:974-981

Gomez-Guzman M, Toral M, Romero M, Jimenez R, Galindo P, Sanchez M, Zarzuelo MJ, Olivares M, Galvez J, Duarte J (2015) Antihypertensive effects of probiotics Lactobacillus strains in spontaneously hypertensive rats. Mol Nutr Food Res 59:23262336

Gozd-Barszczewska A, Koziol-Montewka M, Barszczewski P, Mlodzinska A, Huminska K (2017) Gut microbiome as a biomarker of cardiometabolic disorders. Ann Agric Environ Med 24:416-422

Halkjaer SI, Christensen AH, Lo BZS, Browne PD, Gunther S, Hansen LH, Petersen AM (2018) Faecal microbiota transplantation alters gut microbiota in patients with irritable bowel syndrome: results from a randomised, double-blind placebocontrolled study. Gut 67:2107-2115

He K, Hu Y, Ma H, Zou Z, Xiao Y, Yang Y, Feng M, Li X, Ye X (2016) Rhizoma Coptidis alkaloids alleviate hyperlipidemia in $\mathrm{B} 6$ mice by modulating gut microbiota and bile acid pathways. Biochim Biophys Acta 1862:1696-1709

Honour JW, Borriello SP, Ganten U, Honour P (1985) Antibiotics attenuate experimental hypertension in rats. $\mathrm{J}$ Endocrinol 105:347-350

Huang Y, Wang J, Quan G, Wang X, Yang L, Zhong L (2014) Lactobacillus acidophilus ATCC 4356 prevents atherosclerosis via inhibition of intestinal cholesterol absorption in apolipoprotein E-knockout mice. Appl Environ Microbiol 80:7496-7504

Isabella VM, Ha BN, Castillo MJ, Lubkowicz DJ, Rowe SE, Millet YA, Anderson CL, Li N, Fisher AB, West KA et al (2018) Development of a synthetic live bacterial therapeutic for the human metabolic disease phenylketonuria. Nat Biotechnol 36:857-864

Jie Z, Xia H, Zhong SL, Feng Q, Li S, Liang S, Zhong H, Liu Z, Gao $\mathrm{Y}, \mathrm{Zhao} \mathrm{H}$ et al (2017) The gut microbiome in atherosclerotic cardiovascular disease. Nat Commun 8:845

Jin M, Qian Z, Yin J, Xu W, Zhou X (2019) The role of intestinal microbiota in cardiovascular disease. J Cell Mol Med 23:23432350

Kamo T, Akazawa H, Suda W, Saga-Kamo A, Shimizu Y, Yagi H, Liu Q, Nomura S, Naito AT, Takeda N et al (2017) Dysbiosis and compositional alterations with aging in the gut microbiota of patients with heart failure. PLoS ONE 12:e0174099

Karlsson C, Ahrne S, Molin G, Berggren A, Palmquist I, Fredrikson GN, Jeppsson B (2010) Probiotic therapy to men with incipient 
arteriosclerosis initiates increased bacterial diversity in colon: a randomized controlled trial. Atherosclerosis 208:228-233

Karlsson FH, Fak F, Nookaew I, Tremaroli V, Fagerberg B, Petranovic D, Backhed F, Nielsen J (2012) Symptomatic atherosclerosis is associated with an altered gut metagenome. Nat Commun 3:1245

Kasahara K, Krautkramer KA, Org E, Romano KA, Kerby RL, Vivas EI, Mehrabian M, Denu JM, Backhed F, Lusis AJ et al (2018) Interactions between Roseburia intestinalis and diet modulate atherogenesis in a murine model. Nat Microbiol 3:1461-1471

Khalesi S, Sun J, Buys N, Jayasinghe R (2014) Effect of probiotics on blood pressure: a systematic review and meta-analysis of randomized, controlled trials. Hypertension 64:897-903

Khalesi S, Bellissimo N, Vandelanotte C, Williams S, Stanley D, Irwin C (2019) A review of probiotic supplementation in healthy adults: helpful or hype? Eur J Clin Nutr 73:24-37

Koeth RA, Wang Z, Levison BS, Buffa JA, Org E, Sheehy BT, Britt EB, Fu X, Wu Y, Li L et al (2013) Intestinal microbiota metabolism of L-carnitine, a nutrient in red meat, promotes atherosclerosis. Nat Med 19:576-585

Lam V, Su J, Koprowski S, Hsu A, Tweddell JS, Rafiee P, Gross GJ, Salzman NH, Baker JE (2012) Intestinal microbiota determine severity of myocardial infarction in rats. FASEB J 26:1727-1735

Lam V, Su J, Hsu A, Gross GJ, Salzman NH, Baker JE (2016) Intestinal microbial metabolites are linked to severity of myocardial infarction in rats. PLoS ONE 11:e0160840

Lam KN, Alexander M, Turnbaugh PJ (2019) Precision medicine goes microscopic: engineering the microbiome to improve drug outcomes. Cell Host Microbe 26:22-34

Li M, Shu X, Xu H, Zhang C, Yang L, Zhang L, Ji G (2016) Integrative analysis of metabolome and gut microbiota in diet-induced hyperlipidemic rats treated with berberine compounds. J Transl Med 14:237

Li J, Zhao F, Wang Y, Chen J, Tao J, Tian G, Wu S, Liu W, Cui Q, Geng B et al (2017a) Gut microbiota dysbiosis contributes to the development of hypertension. Microbiome 5:14

Li XS, Obeid S, Klingenberg R, Gencer B, Mach F, Raber L, Windecker S, Rodondi N, Nanchen D, Muller O et al (2017b) Gut microbiota-dependent trimethylamine $\mathrm{N}$-oxide in acute coronary syndromes: a prognostic marker for incident cardiovascular events beyond traditional risk factors. Eur Heart J 38:814-824

Libby P, Ridker PM, Maseri A (2002) Inflammation and atherosclerosis. Circulation 105:1135-1143

Lopez-Mejias R, Genre F, Garcia-Bermudez M, Ubilla B, Castaneda S, Llorca J, Gonzalez-Juanatey C, Corrales A, Miranda-Filloy JA, Pina T et al (2014) Lack of association between ABO, PPAP2B, ADAMST7, PIK3CG, and EDNRA and carotid intima-media thickness, carotid plaques, and cardiovascular disease in patients with rheumatoid arthritis. Mediators Inflamm 2014:756279

Luedde M, Winkler T, Heinsen FA, Ruhlemann MC, Spehlmann ME, Bajrovic A, Lieb W, Franke A, Ott SJ, Frey N (2017) Heart failure is associated with depletion of core intestinal microbiota. ESC Heart Fail 4:282-290

Mamic P, Heidenreich PA, Hedlin H, Tennakoon L, Staudenmayer $\mathrm{KL}$ (2016) Hospitalized patients with heart failure and common bacterial infections: a nationwide analysis of concomitant clostridium difficile infection rates and in-hospital mortality. J Card Fail 22:891-900

Marques FZ, Nelson E, Chu PY, Horlock D, Fiedler A, Ziemann M, Tan JK, Kuruppu S, Rajapakse NW, El-Osta A et al (2017) Highfiber diet and acetate supplementation change the gut microbiota and prevent the development of hypertension and heart failure in hypertensive mice. Circulation 135:964-977

Maruvada P, Leone V, Kaplan LM, Chang EB (2017) The human microbiome and obesity: moving beyond associations. Cell Host Microbe 22:589-599

Mell B, Jala VR, Mathew AV, Byun J, Waghulde $H$, Zhang $Y$, Haribabu B, Vijay-Kumar M, Pennathur S, Joe B (2015) Evidence for a link between gut microbiota and hypertension in the Dahl rat. Physiol Genomics 47:187-197

Mencarelli A, Cipriani S, Renga B, Bruno A, D'Amore C, Distrutti E, Fiorucci S (2012) VSL\#3 resets insulin signaling and protects against $\mathrm{NASH}$ and atherosclerosis in a model of genetic dyslipidemia and intestinal inflammation. PLoS ONE 7:e45425

Molin G (2001) Probiotics in foods not containing milk or milk constituents, with special reference to Lactobacillus plantarum 299v. Am J Clin Nutr 73:380S-385S

Naruszewicz M, Johansson ML, Zapolska-Downar D, Bukowska H (2002) Effect of Lactobacillus plantarum 299v on cardiovascular disease risk factors in smokers. Am J Clin Nutr 76:1249-1255

Natarajan N, Hori D, Flavahan S, Steppan J, Flavahan NA, Berkowitz DE, Pluznick JL (2016) Microbial short chain fatty acid metabolites lower blood pressure via endothelial G proteincoupled receptor 41. Physiol Genomics 48:826-834

Nemet I, Saha PP, Gupta N, Zhu W, Romano KA, Skye SM, Cajka T, Mohan ML, Li L, Wu Y et al (2020) A cardiovascular diseaselinked gut microbial metabolite acts via adrenergic receptors. Cell 180(862-877):e822

Ott SJ, El Mokhtari NE, Musfeldt M, Hellmig S, Freitag S, Rehman A, Kuhbacher T, Nikolaus S, Namsolleck P, Blaut M et al (2006) Detection of diverse bacterial signatures in atherosclerotic lesions of patients with coronary heart disease. Circulation 113:929-937

Ozdal T, Sela DA, Xiao J, Boyacioglu D, Chen F, Capanoglu E (2016) The reciprocal interactions between polyphenols and gut microbiota and effects on bioaccessibility. Nutrients 8:78

Pasini E, Aquilani R, Testa C, Baiardi P, Angioletti S, Boschi F, Verri M, Dioguardi F (2016) Pathogenic gut flora in patients with chronic heart failure. JACC Heart Fail 4:220-227

Pluznick J (2014) A novel SCFA receptor, the microbiota, and blood pressure regulation. Gut Microbes 5:202-207

Pluznick JL, Protzko RJ, Gevorgyan H, Peterlin Z, Sipos A, Han J, Brunet I, Wan LX, Rey F, Wang T et al (2013) Olfactory receptor responding to gut microbiota-derived signals plays a role in renin secretion and blood pressure regulation. Proc Natl Acad Sci USA 110:4410-4415

Poesen R, Claes K, Evenepoel P, de Loor H, Augustijns P, Kuypers D, Meijers B (2016) Microbiota-derived phenylacetylglutamine associates with overall mortality and cardiovascular disease in patients with CKD. J Am Soc Nephrol 27:3479-3487

Portugal LR, Goncalves JL, Fernandes LR, Silva HP, Arantes RM, Nicoli JR, Vieira LQ, Alvarez-Leite JI (2006) Effect of Lactobacillus delbrueckii on cholesterol metabolism in germ-free mice and 
on atherogenesis in apolipoprotein E knock-out mice. Braz J Med Biol Res 39:629-635

Qi Y, Aranda JM, Rodriguez V, Raizada MK, Pepine CJ (2015) Impact of antibiotics on arterial blood pressure in a patient with resistant hypertension-a case report. Int J Cardiol 201:157-158

Qin J, Li R, Raes J, Arumugam M, Burgdorf KS, Manichanh C, Nielsen T, Pons N, Levenez F, Yamada T et al (2010) A human gut microbial gene catalogue established by metagenomic sequencing. Nature 464:59-65

Rajendhran J, Shankar M, Dinakaran V, Rathinavel A, Gunasekaran P (2013) Contrasting circulating microbiome in cardiovascular disease patients and healthy individuals. Int J Cardiol 168:51185120

Roberts AB, Gu X, Buffa JA, Hurd AG, Wang Z, Zhu W, Gupta N, Skye SM, Cody DB, Levison BS et al (2018) Development of a gut microbe-targeted nonlethal therapeutic to inhibit thrombosis potential. Nat Med 24:1407-1417

Ronda C, Chen SP, Cabral V, Yaung SJ, Wang HH (2019) Metagenomic engineering of the mammalian gut microbiome in situ. Nat Methods 16:167-170

Sandek A, Bauditz J, Swidsinski A, Buhner S, Weber-Eibel J, von Haehling S, Schroedl W, Karhausen T, Doehner W, Rauchhaus M et al (2007) Altered intestinal function in patients with chronic heart failure. J Am Coll Cardiol 50:1561-1569

Sandek A, Bjarnason I, Volk HD, Crane R, Meddings JB, Niebauer J, Kalra PR, Buhner S, Herrmann R, Springer J et al (2012) Studies on bacterial endotoxin and intestinal absorption function in patients with chronic heart failure. Int J Cardiol 157:80-85

Santisteban MM, Qi Y, Zubcevic J, Kim S, Yang T, Shenoy V, ColeJeffrey CT, Lobaton GO, Stewart DC, Rubiano A et al (2017) Hypertension-linked pathophysiological alterations in the gut. Circ Res 120:312-323

Sekirov I, Russell SL, Antunes LC, Finlay BB (2010) Gut microbiota in health and disease. Physiol Rev 90:859-904

Seldin MM, Meng Y, Qi H, Zhu W, Wang Z, Hazen SL, Lusis AJ, Shih DM (2016) Trimethylamine N-oxide promotes vascular inflammation through signaling of mitogen-activated protein kinase and nuclear factor-kappaB. J Am Heart Assoc 5.

Senthong V, Wang Z, Fan Y, Wu Y, Hazen SL, Tang WH (2016a) Trimethylamine $\mathrm{N}$-oxide and mortality risk in patients with peripheral artery disease. J Am Heart Assoc 5.

Senthong V, Wang Z, Li XS, Fan Y, Wu Y, Tang WH, Hazen SL (2016b) Intestinal microbiota-generated metabolite trimethylamine-N-oxide and 5-year mortality risk in stable coronary artery disease: the contributory role of intestinal microbiota in a COURAGE-like patient cohort. J Am Heart Assoc 5.

Shimizu M, Hashiguchi M, Shiga T, Tamura HO, Mochizuki M (2015) Meta-analysis: effects of probiotic supplementation on lipid profiles in normal to mildly hypercholesterolemic individuals. PLoS ONE 10:e0139795

Tang WH, Hazen SL (2017) The gut microbiome and its role in cardiovascular diseases. Circulation 135:1008-1010

Tang WH, Wang Z, Levison BS, Koeth RA, Britt EB, Fu X, Wu Y, Hazen SL (2013) Intestinal microbial metabolism of phosphatidylcholine and cardiovascular risk. N Engl J Med 368:1575-1584

Tang WH, Wang Z, Fan Y, Levison B, Hazen JE, Donahue LM, Wu Y, Hazen SL (2014) Prognostic value of elevated levels of intestinal microbe-generated metabolite trimethylamine- $\mathrm{N}$-oxide in patients with heart failure: refining the gut hypothesis. J Am Coll Cardiol 64:1908-1914

Tang WH, Wang Z, Shrestha K, Borowski AG, Wu Y, Troughton RW, Klein AL, Hazen SL (2015) Intestinal microbiota-dependent phosphatidylcholine metabolites, diastolic dysfunction, and adverse clinical outcomes in chronic systolic heart failure. J Card Fail 21:91-96

Trichopoulou A, Bamia C, Trichopoulos D (2009) Anatomy of health effects of Mediterranean diet: Greek EPIC prospective cohort study. BMJ 338:b2337

Turnbaugh PJ (2020) Diet should be a tool for researchers, not a treatment. Nature 577:S23

Vaghef-Mehrabany E, Vaghef-Mehrabany L, Asghari-Jafarabadi M, Homayouni-Rad A, Issazadeh K, Alipour B (2017) Effects of probiotic supplementation on lipid profile of women with rheumatoid arthritis: A randomized placebo-controlled clinical trial. Health Promot Perspect 7:95-101

van Nood E, Vrieze A, Nieuwdorp M, Fuentes S, Zoetendal EG, de Vos WM, Visser CE, Kuijper EJ, Bartelsman JF, Tijssen JG et al (2013) Duodenal infusion of donor feces for recurrent Clostridium difficile. N Engl J Med 368:407-415

Vrieze A, Van Nood E, Holleman F, Salojarvi J, Kootte RS, Bartelsman JF, Dallinga-Thie GM, Ackermans MT, Serlie MJ, Oozeer $R$ et al (2012) Transfer of intestinal microbiota from lean donors increases insulin sensitivity in individuals with metabolic syndrome. Gastroenterology 143(913-916):e917

Walter J, Armet AM, Finlay BB, Shanahan F (2020) Establishing or exaggerating causality for the gut microbiome: lessons from human microbiota-associated rodents. Cell 180:221-232

Wang Z, Zhao Y (2018) Gut microbiota derived metabolites in cardiovascular health and disease. Protein Cell 9:416-431

Wang Z, Klipfell E, Bennett BJ, Koeth R, Levison BS, Dugar B, Feldstein AE, Britt EB, Fu X, Chung YM et al (2011) Gut flora metabolism of phosphatidylcholine promotes cardiovascular disease. Nature 472:57-63

Wang Z, Tang WH, Buffa JA, Fu X, Britt EB, Koeth RA, Levison BS, Fan Y, Wu Y, Hazen SL (2014) Prognostic value of choline and betaine depends on intestinal microbiota-generated metabolite trimethylamine-N-oxide. Eur Heart J 35:904-910

Wang Z, Roberts AB, Buffa JA, Levison BS, Zhu W, Org E, Gu X, Huang Y, Zamanian-Daryoush M, Culley MK et al (2015) Nonlethal inhibition of gut microbial trimethylamine production for the treatment of atherosclerosis. Cell 163:1585-1595

Wang L, Zhu Q, Lu A, Liu X, Zhang L, Xu C, Liu X, Li H, Yang T (2017) Sodium butyrate suppresses angiotensin II-induced hypertension by inhibition of renal (pro)renin receptor and intrarenal renin-angiotensin system. J Hypertens 35:1899-1908

Wilck N, Matus MG, Kearney SM, Olesen SW, Forslund $K$, Bartolomaeus $\mathrm{H}$, Haase S, Mahler A, Balogh A, Marko $L$ et al (2017) Salt-responsive gut commensal modulates TH17 axis and disease. Nature 551:585-589

Wu XM, Tan RX (2019) Interaction between gut microbiota and ethnomedicine constituents. Nat Prod Rep 36:788-809

Xiao S, Fei N, Pang X, Shen J, Wang L, Zhang B, Zhang M, Zhang X, Zhang C, Li M et al (2014) A gut microbiota-targeted dietary 
intervention for amelioration of chronic inflammation underlying metabolic syndrome. FEMS Microbiol Ecol 87:357-367

Xu Z, Knight R (2015) Dietary effects on human gut microbiome diversity. Br J Nutr 113(Suppl):S1-5

Xue L, He J, Gao N, Lu X, Li M, Wu X, Liu Z, Jin Y, Liu J, Xu J et al (2017) Probiotics may delay the progression of nonalcoholic fatty liver disease by restoring the gut microbiota structure and improving intestinal endotoxemia. Sci Rep 7:45176

Yan Q, Gu Y, Li X, Yang W, Jia L, Chen C, Han X, Huang Y, Zhao L, $\mathrm{Li} P$ et al (2017) Alterations of the gut microbiome in hypertension. Front Cell Infect Microbiol 7:381

Yang T, Santisteban MM, Rodriguez V, Li E, Ahmari N, Carvajal JM, Zadeh M, Gong M, Qi Y, Zubcevic J et al (2015) Gut dysbiosis is linked to hypertension. Hypertension 65:1331-1340

Zhang F, Cui B, He X, Nie Y, Wu K, Fan D, Group FMSS (2018) Microbiota transplantation: concept, methodology and strategy for its modernization. Protein Cell 9:462-473

Zhang F, Zhang T, Zhu H, Borody TJ (2019) Evolution of fecal microbiota transplantation in methodology and ethical issues. Curr Opin Pharmacol 49:11-16

Zhou X, Li J, Guo J, Geng B, Ji W, Zhao Q, Li J, Liu X, Liu J, Guo Z et al (2018) Gut-dependent microbial translocation induces inflammation and cardiovascular events after ST-elevation myocardial infarction. Microbiome 6:66

Zhu W, Lin K, Li K, Deng X, Li C (2018) Reshaped fecal gut microbiota composition by the intake of high molecular weight persimmon tannin in normal and high-cholesterol diet-fed rats. Food Funct 9:541-551

Ziganshina EE, Sharifullina DM, Lozhkin AP, Khayrullin RN, Ignatyev IM, Ziganshin AM (2016) Bacterial communities associated with atherosclerotic plaques from russian individuals with atherosclerosis. PLoS ONE 11:e0164836

Zuo K, Li J, Li K, Hu C, Gao Y, Chen M, Hu R, Liu Y, Chi H, Wang H et al (2019a) Disordered gut microbiota and alterations in metabolic patterns are associated with atrial fibrillation. Gigascience 8.

Zuo K, Li J, Wang P, Liu Y, Liu Z, Yin X, Liu X, Yang X (2019b) Duration of persistent atrial fibrillation is associated with alterations in human gut microbiota and metabolic phenotypes. mSystems 4.

Zuo K, Li J, Xu Q, Hu C, Gao Y, Chen M, Hu R, Liu Y, Chi H, Yin Q et al (2019c) Dysbiotic gut microbes may contribute to hypertension by limiting vitamin D production. Clin Cardiol 42:710-719 